\title{
O religioso na rede: interações e discursos nas religiões 2.0
}

\author{
The religious on web: interactions and discourse in the religions 2.0
}

\section{Lo religioso en la red: interacciones y discursos en las religiones 2.0}

\author{
Adriana Do Amaral Freire ${ }^{l}$ \\ Karla Regina Macena Pereira Patriota Bronsztein ${ }^{2}$
}

\section{Resumo}

A ação de instituições religiosas no ambiente cultural das mídias digitais nos leva a perceber a emergência do que vem sendo também definido como Religião 2.0, conceito que propomos sopesar nesta reflexão.Para delimitar o universo de análise no ciberespaço e ilustrar o fenômeno a partir de um exemplo real, selecionamos como objeto os conteúdos digitais produzidos por/para umas das novas celebridades do catolicismo, o padre Reginaldo Manzotti, este assume a imagem de uma celebridade da fé católica, um popstar midiático que desponta direto de igrejas locais para as mídias digitais, numa perspectiva de abrangência nacional. Com este trabalho, portanto, pretendemos observar, especificamente, o que configura a religião 2.0e como estainfluencia e interfere na cultura religiosa. Em paralelo, pretendemos observar a construção da imagem de uma celebridade da fé na web e como tal imagem pretende influenciara vivênciareligiosa dos fiéis.

Palavras-chave: Religião 2.0. Reginaldo Manzotti. Ciber-igreja. Ciber-fiel. Religião do consumo.

\section{Abstract}

The action of religious institutions in the cultural environment of digital media leads us to realize the emergence of what has been also defined as Religion 2.0, a concept that we propose to consider in this reflection. To define the universe of analysis in cyberspace and illustrate the phenomenon from a real example, we selected as object of study the digital content produced by / for a new celebrity of Catholicism, the priest Reginaldo Manzotti, that assumes the image of a Catholic church celebrity, a media pop star that emerges directly from local churches to digital media, a nationwide perspective. With this work, therefore, we pretend to observing specifically what configure the religion 2.0, how it influences and interferes in religious culture. At the same time, we plan to observe a celebrity of the faith image construction on the web and how this can influence the religious life experience of its followers.

\begin{tabular}{|c|c|}
\hline \multicolumn{2}{|r|}{ Acesse este artigo online } \\
\hline QR CODE: & $\begin{array}{l}\text { Website: } \\
\text { http://www.revistas.ufg.br/index.php/ci }\end{array}$ \\
\hline $\begin{array}{l}b^{2} \\
y^{4} y^{2}\end{array}$ & $\begin{array}{l}\text { DOI: } \\
\text { http://dx.doi.org/10.5216/36820 }\end{array}$ \\
\hline
\end{tabular}

Keywords: Religion 2.0. Reginaldo Manzotti. Cyber-church. Cyber-faith follower. Consumption religion.

\section{Resumen}

La acción de las Instituciones religiosas, en el ambiente cultural de los medios digitales, nos lleva a mirar hacia la emergencia de lo

\footnotetext{
${ }^{1}$ Doutoranda no Programa de Pós-graduação em Comunicação da Universidade Federal de Pernambuco (PPGCOM/UFPE). Mestra em Extensão Rural e Desenvolvimento Local pela Universidade Federal Rural de Pernambuco (UFRPE). Professora da Universidade Federal da Paraíba (UFPB). Brasil, Paraíba, João Pessoa. Email: adriana.amaral@gmail.com

${ }^{2}$ Pós-doutora em Antropologia Social pela Universidade de Cambridge, Reino Unido. Doutora em Sociologia e mestre em Comunicação pela Universidade Federal de Pernambuco (UFPE). Professora do Programa de Pósgraduação em Comunicação da Universidade (PPGCOM) da UFPE. Brasil, Pernambuco, Recife. E-mail: k.patriota@gmail.com
}

Comun. \& Inf., Goiânia, GO, v. 18, n. 2, p. 36-52, jul./dez. 2015 
que también se ha definido cómo la Religión 2.0, concepto que proponemos sopesar en esta reflexión. Para definir el universo de análisis en el ciberespacio e ilustrar el fenómeno con un ejemplo real, seleccionamos cómo objeto del estudio el contenido digital producido por/para la nueva celebridad del catolicismo, el sacerdote Reginaldo Manzotti, que asume la imagen de una celebridad de la iglesia católica, un astro pop de los medios que surge directamente de las iglesias locales para los medios digitales, en una perspectiva nacional. Con este trabajo, por lo tanto, se pretende observar específicamente lo que establece la religión 2.0 y cómo esta influye e interfiere en la cultura religiosa. Al mismo tiempo, tenemos la intención de observar la construcción de la imagen de una celebridad de la fe en la web y cómo esto puede influir en la experiencia de la vida religiosa de sus seguidores.

Palabras clave: Religión 2.0. Reginaldo Manzotti. Cyber-iglesia. Cyber-fiel. Religión del consumo.

\section{INTRODUÇÃO}

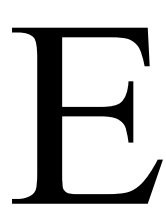

$\mathrm{m}$ tempos de cultura ciber um dos "lugares" para encontrar a "Deus" passa a ser o Google.Numa busca rápida são localizadas mais de 168.000.000 (cento

e sessenta e oito milhões $)^{3}$ de referências ao Criador do universo.A internet, de forma geral, passa a oferecer, cada vez mais, soluções no âmbito espiritual para aqueles que buscam respostas às suas inquietações existenciais que podem ser minimizadas pela via da fé e do sagrado. Para pesquisadores que se interessam pelos estudos das religiosidades, cresce também o interesse em saber quais são os resultados que as mídias digitais e as práticas interativas da internet vêm promovendo no contexto da fé religiosa. O que parece evidente, vem sendo demonstrado em estudos recentes de pesquisadores como Miklos (2012), Spadaro (2012), Sbardeloto (2012) e outros, é que uma nova forma de praticar e seguir preceitos religiosos vem se definindo.

Igualmente surgem novas formas de promover e disseminar os discursos religiososno atual cenário. Com efeito, emerge e se consolida rapidamente nos espaços daweb, um traço peculiar da cibercultura, que precisa ser delimitado, observado e melhor definido.Estudiosos de mídia e religião, em tentativas frutíferas, vêm desenhando conceitos que pretendem demarcar o fenômeno, classificado de diversas formas: como uma "ciber-religião", enquanto prática (MIKLOS, 2012); como "Ciberteologia", enquanto ciência (SPADARO, 2012); como Digital Religion, constituída através da cultura das mídias digitais (H. CAMPBELL, 2013); ou como "religião 2.0", tema do evento Eclesiocom 2011 - que discute a temática religiosa atrelada à comunicação midiática - e de um dos novos fóruns de pesquisa do Congresso Internacionale Bianual de Sociologia das Religiõesque aconteceuna Bélgica, o ISSR 2015. Essa diversidade de abordagens comprovada como fenômeno tem suscitado distintos olhares, acirrando um debate mais frequente sobre a internet como lócus de essência ubíqua (assim como a noção de

\footnotetext{
${ }^{3}$ Acesso em: em 27 de jan de 2015.
}

Comun. \& Inf., Goiânia, GO, v. 18, n. 2, p. 36-52, jul./dez. 2015 
Deus, presente simultaneamente em todos os lugares) e também religiosa,com a sua crescente invisibilidade que se dissolve no cotidiano humano e nos faz seres conectados 24 horas por dia. Isso nos leva à ponderar que, quando a internet se dissolver completamente no cotidiano das pessoas, certamente, serão as redes sociais digitais as formas mais naturalizadas de uso desta. Confirmando-se a ideia de uma internetsimbiotizada no cotidiano, fortalece-se ainda mais a teoria de uma cultura dociber e, como toda a esfera do real pode ser transposta para o ambiente digital, o contexto sagrado da fé há de naturalizar-se também na esfera virtual.

Por outro lado, igualmente é real o fato de que as interações nas esferas presenciais não irão desaparecer, porém podem co-existir com as práticas virtuais, como hoje é comum um grupo de amigos que, reunido em uma mesa de bar, falem ao mesmo tempo, pelo celular e com outras pessoas no Whatsapp ${ }^{4}$, inclusive estando na mesma mesa. O mesmo pode acontecer em ambientes presenciais de fé, integrando a religiosidade tradicional com a religião 2.0.

Inicialmente, o que poderia diferenciar a religião 2.0 das formas tradicionais de vivência religiosa, é que esta pode ser praticada sem qualquer limitação espacial, exceto pela ausência de conexão com a internet. Pelo YouTube ${ }^{5}$, por exemplo, é possível acessar vídeos de todos os tipos prováveis de religiosidade, desde rituais indígenas secretos a práticas do candomblé, cultos evangélicos, missas católicas, rituais de magia negra e tantos outros, é só imaginar e buscar. Descrições, conversação em redes, doutrinas, documentos sagrados, ensinamentos, são também facilmente encontrados em sites, blogs e perfis em redes sociais dos mais diversos formatos.

Tal diversidade de conteúdos e formasfornece à religião 2.0 um contexto borrado de práticas sincretizadas, que auxiliam no surgimento de uma religiosidade igualmente borrada, bricolada e controversa. Exatamente como nos propõe Hervieu-Léger (1999) ao abordar a vivência religiosa na contemporaneidade, revelando, de um lado, a "desregulação institucional" da religiosidade e, de outro, a disseminação de novas formas de expressão religiosa: de uma religiosidade "flutuante", nascida da "bricolage $6 "$ (HERVIEU-LÉGER, 1999 apud BRONSZTEIN; SALUSTIANO, 2014).

A oferta diversificada de conteúdos e tipos religiosos potencializa a ideia de consumo religioso, BRONSZTEIN fala de uma "religião do consumo" e a define como um "formato de religiosidade que se estrutura e cresce na medida em que estimula e promove o consumo como

\footnotetext{
${ }^{4}$ Aplicativo de celular que permite conversação por chat e troca de arquivos (de imagem, texto e som) em tempo real, demandando conexão com a internet.

${ }^{5}$ Site que permite que seus usuários carreguem e compartilhem vídeos em formato digital.

${ }^{6}$ União de vários elementos culturais para a formação de uma identidade e narrativa próprias.
}

Comun. \& Inf., Goiânia, GO, v. 18, n. 2, p. 36-52, jul./dez. 2015 
resposta ao ideal de felicidade proveniente de uma boa relação com Deus" (BRONSZTEIN, 2014, p. 128). Esse consumo, hoje, é abrangente e redentor: vai do âmbito de bens físicos à bens de sentido simbólico, como ouvir a música ou assistir ao programa na tevê de uma determinada personalidade famosa do universo religioso na web, por exemplo.

Os lugares virtuais passam a possibilitarações antes praticadas apenas no âmbito presencial, como acender velas ou participar de uma jogada de búzios (ritual presente nas práticas das religiões de matrizes africanas). O mais interessante é que pessoas que antes frequentavam apenas uma religião no contexto presencial, no ambiente virtual têm a possibilidade de experimentaroutras culturas religiosas, de transitar por esferas distintas de fé. Mais que isso, estes indivíduos adquirem um poder de expressão e disseminação do seu próprio conceito de sagrado.Corrobora com esta afirmação o que Lemos (2013) conclui sobre cibercultura, ao afirmar que:

O ciberespaço é um ambiente de circulação de discussões pluralistas, reforçando competências diferenciadas e aproveitando o caldo de conhecimento que é gerado dos laços comunitários, podendo potencializar a troca de competências, gerando a coletivização dos saberes (LEMOS, 2013, p. 136).

Tal potencial de mudança que a tecnologia das redes sociais digitais adquire, contribuindo, inclusive, para o surgimento de uma nova cultura, mais participativa, colaborativa e dialógica, de uma cibercultura, como classificam Levy (1996) e Lemos (2013), vai favorecer igualmente a formatação de uma religiosidade de exterioridade diferente (mesmo que preserve o conteúdo anterior), na verdade uma "ciberreligiosidade", nascida com o que se convencionou chamar de web 2.0.

É importante destacar, por conseguinte, que a cultura ciber não está consolidada, nem é estática, ao contrário, quando falamos de religião 2.0, fazendo alusão ao termo Web 2.0 - que por sua vez remete ao grau de tecnologia e potenciabilidades de rede, sobre a qual já se especula uma quarta fase, a da $\mathrm{Web}_{4} .0^{7}$ - pressupõe-se a ideia de transformação e desenvolvimento.Esse estado de transformação constante a que está submetida a tecnologia causa a incerteza do que vem depois, sobre o que esperar em termos de tecnologia da informação e comunicação posteriormente a internet, como refletiu Wolton (2012)no livro, “Internet e depois?".

Sobre religião digital, H. Campbell (2013) observa uma nova esfera em que "mídias sociais e cultura desenham juntas um campo de estudos que reflete a complexa relação que

\footnotetext{
${ }^{7}$ Já se encontra definições sobre o termo, que determina uma web fundamentada em tecnologia móvel.
} 


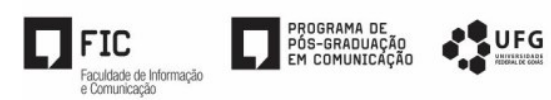

emerge entre mídia digital e religiosidade contemporânea, no mundo da web 2.0"8. A autora busca delimitar um campo ao qual classifica como sendo um subcampo dos estudos de mídias sociais e apresenta três objetivos para a sua pesquisa, que são: o de mostrar como o estudo de religião e novas mídias é vibrante e válido; o de mapear outras escolas que investigam o tema; eo de buscar saber o que cada escola vem inquirindo sobre a "digital religion".

Pelo texto de H. Campbell (2013) é possível perceber como a religião digital passa, naturalmente, a integrar o campo da cultura de mídia on-line e incorporá-lo às suas práticas e doutrinas. A autora observa como tradições religiosas estão se engajando com uma variedade de formas de novas mídias (blogs, telefones celulares, Second Life, vídeo games, websites etc.). O estudo de H. Campbell (2013) é inspirador para aportar a ideia de religião 2.0 que, como a religião digital, significa a relação cada vez mais dinâmica entre espiritualidade e web.

No contexto das mídias digitais, a religião emerge como prática cada vez mais interativa e colaborativa. As instituições religiosas (referindo-se aqui aos mais variados tipos de religiões e doutrinas) se apropriam de tais recursos tecnológicos, assumindo a necessidade de promover o engajamento de seus públicos nas suas práticas virtuais.

O Padre Reginaldo Manzotti, por exemplo, um padre cantor que já realiza shows e aparições na tevê, possui toda uma estrutura integrada de mídias on-line. No site ${ }^{9}$ do Padre estão links para a sua fanpage, canal no Youtube e perfil no Twitter, todos com números bem expressivos de fãs.

O personagem da análise compõe a imagem de uma celebridade da fé católica, um popstar midiático que, como todos os outros, se apropria dos meios tecnológicos para disseminar seus conteúdos e construir a sua imagem, enquanto novo popstar do catolicismo. Por estar presente na web e ter a religião como razão para as suas práticas, pode-se considerar que o Padre (ou sua assessoria de comunicação) produz conteúdos que integramo tecido, cada vez mais extenso, da religião 2.0 .

Nessa perspectiva a pesquisa propõe realizar uma abordagem sobre a religião 2.0, a partir da observação de conteúdos e recursos presentes no site e redes sociais do Padre Reginaldo Manzotti, intentando obter respostas sobre o objeto e discorrer sobre os elementos que emergem nesse cenário, que envolve a tríade formada por mídia, cultura de consumo e religião.Para compor as amostras que serão utilizadas na pesquisa, a partir de seleção das publicações do Twitter, como nestarede o Padre postou um pouco mais de seis mil mensagens,

\footnotetext{
${ }^{8}$ Tradução das autoras.

${ }^{9}$ Disponível em: <http://www.padrereginaldomanzotti.org.br/>. Acesso em: 12 jan. 2015.
}

Comun. \& Inf., Goiânia, GO, v. 18, n. 2, p. 36-52, jul./dez. 2015 
decidimos por uma amostra não-probabilística e qualitativa de $0,1 \%$ desse total publicado, ou seja, seis tweets, que serão retirados dos últimos seis meses de postagens. Como no Facebook não está disponível o número de publicações realizadas, seguiremos o mesmo número e forma de seleção de amostras do Twitter, ou seja, seis publicações retiradas de semanas alternadas dos últimos seis meses. Por causa da limitação espacial imposta pelo formato do artigo proposto, não realizaremos análises de conteúdos do Youtube e também não dos comentários de usuários que interagem com os perfis. As amostras serão apresentadas em formato de tabelas e categorizadas conforme o teor da mensagem, situadas nos tópicos a seguir.

No contexto, tambémse posicionam e auxiliam na definição de religião 2.0 , os conceitos de ciber-igreja e ciber-fiel, interatores do ambiente on-line. A partir do panorama descritovêm a tona questões sobre o que diferencia a nova religião 2.0, como se formata, como interfere na cultura religiosa e como atua na plataforma da cibercultura.Também pretende-se observar a construção da imagem de uma celebridade da fé na web e como essa incide sobre a atmosfera do consumo simbólico dos fiéis.Nesse sentido pretende-se, a partir de dados netnográficos, descrever o personagem que apresentamos como referência e relatar como este se posiciona na plataforma virtual; em seguida analisar o conteúdo selecionado na perspectiva de observar a construção da imagem, promoção e marketing do personagem; e, ao final, pensar a religião 2.0 a partir do que foi observado nas análises anteriores,ressaltando a manifestação dos movimentos culturais interativos e colaborativos entre ciber-igrejas e ciber-fiéis.

\section{O PADRE REGINALDO MANZOTTI E SUA PRESENÇA NA WEB}

O Padre Reginaldo Manzotti nasceu em 25 de abril de 1970, no município de Paraíso do Norte, no estado do Paraná. É o caçula dos seis filhos de Antônio Manzotti e Percília Maria Manzotti, uma tradicional família de descendentes italianos. Estudou Filosofia e Teologia no Instituto Vicentino de Filosofia (reconhecendo este curso posteriormente pela Universidade de São Paulo) e Studium Theologicum (reconhecendo este curso pela Universidade Lateranense de Roma). Aos 25 anos de idade, foi ordenado Sacerdote em sua cidade natal, Paraíso do Norte. Tem atualmente, vinte anos de ordenação. ${ }^{10}$

Em 2003criou a associação Evangelizar é Preciso, um movimento de evangelização. Em setembro de 2005, recebeu um convite da rádio Colmeia de Maringá, emissora da Arquidiocese de Maringá, no Paraná, onde passou a retransmitir seu programa "Experiência de

\footnotetext{
${ }^{10}$ Os dados desse parágrafo foram obtidos através de reportagem disponível em:

$<$ http://www.letras.com.br/\#!biografia/padre-reginaldo-manzotti>. Acesso em: 03 fev. 2015.
}

Comun. \& Inf., Goiânia, GO, v. 18, n. 2, p. 36-52, jul./dez. 2015 
Deus". Ainda em 2005, junto à Rádio Colmeia, iniciou a retransmissão de seu programa em parceria com outras rádios, mais de 1500 emissoras. Atualmente Reginaldo Manzotti é diretor da Rádio Evangelizar, em qual ele mesmo apresenta um programa de evangelização. Seu álbum, Sinais do Sagrado, alcançou a sexta posição no TOP 20 ABPD (Associação Brasileira dos Produtores de Discos). O DVD, Creio no Deus do Impossível, ganhou um Disco de PlatinaDuplo pela ABPD, por ter tido mais de 100 mil DVD's vendidos no país. Reginaldo Manzotti é conhecido como o "Padre que reúne multidões", é também coordenador da Associação Evangelizar é Preciso, uma obra de evangelização que conta com milhares de associados em todo o Brasil. É o atual pároco da Igreja Nossa Senhora de Guadalupe, em Curitiba (PR) e, todos os dias, apresenta programas de TV e rádio, transmitidos em todo o País. ${ }^{11}$

$\mathrm{Na}$ internet possui mídias oficiais (site, fanpage, perfil no Twitter e canal no Youtube). O site ${ }^{12}$ oficial é bastante complexo, no topo da página o título, o nome do Padre Reginaldo Manzotti e dois menus, o primeiro contém abas de ajuda, fale conosco, pedidos de oração, receba o boletim e jornal do evangelizador; no segundo menu, estão as abas Início, Testemunhos, Agenda e Fotos, Santuário (que conta com opções de novenas, acendimento de velas virtuais e acesso à orações diversas), Associação, Rádio, TV, Loja Virtual e Associe-se.

Em seguida a imagem do padre, segurando a cruz católica com a imagem de Jesus crucificado, um buscador para buscas rápidas no site e uma janela para fazer o login, além de links para o Twitter, Facebook e canal no Youtube, bem como a logomarca da associação Evangelizar é Preciso. Abaixo um menu com pequenos banners: o primeiro liga a descrição do programa de rádio do Padre, dentro desse link também é possível baixar um banner para colocar como foto de capa do Facebook e há um link para o usuário deixar um testemunho; o segundo banner pergunta se você está preparado para ser mensageiro da misericórdia, espaço explicativo sobre como se tornar um membro da Associação Evangelizar; o terceiro e quarto banners dão acesso ao programa de rádio e programas de TV, sendo o segundo exclusivo para associados ao site; o quinto banner traz arquivos de programas e é restrito para usuários inscritos e; o sexto e último banner é um espaço para contribuição/filiação. Em seguida há um quadro com testemunho de fiéis em destaque, um banner mutável com propagandas institucionais das ações da Instituição a qual o Padre é vinculado, no site há ainda loja virtual, quadro mutável de fotos em destaque, aplicativo para receber mensagens do Padre no celular, canal de vídeos, agenda

\footnotetext{
${ }^{11}$ As informações citadas nesse parágrafo foram retiradas de:

$<$ http://pt.wikipedia.org/wiki/Reginaldo_Manzotti>. Acesso em 13 fev 2014.

${ }^{12}$ Disponível em: <http://www.padrereginaldomanzotti.org.br/?ref=logo $>$. Acesso em: 20 fev. 2014.
}

Comun. \& Inf., Goiânia, GO, v. 18, n. 2, p. 36-52, jul./dez. 2015 
de eventos e outras opções. O ambiente funciona como um blog, em qual é possível rolar a tela para baixo para ver as opções, porém, não disponibiliza apenas publicações, mas aplicativos e quadros dinâmicos, com muitas aplicações e conteúdos dos mais diversos formatos.

Utiliza redes sociais vinculadas ao site principal e, no Twitter (em 22 fev 2015) possui 200.355 (duzentos mil e trezentos e cinquenta e cinco) seguidores, publicou 6093 tweets, utiliza a mídia desde setembro de 2009 , na foto de capa ele está ao centro e a frente de uma multidão que está atrás dele, provavelmente num show. No Facebook (em 22 fev 2015) tem 4.847.303 (quatro milhões e oitocentos e quarenta e sete mil e trezentos e três) de curtidas e está presente desde 2009 nesta rede também. Os conteúdos publicados no Facebook são geralmente replicados no Twitter, ligados por hiperlink, em geral, vídeos de shows, imagens do padre e imagens religiosas, mensagens de fé, músicas e reflexões na perspectiva religiosa.A foto de capa é a mesma nas duas redes (Facebook e Twitter). As postagens, tanto no Twitter como no Facebook, costumam convidar os usuários para assistir os programas de TV e ouvir as músicas e programas no rádio. No canal do Youtube possui uma média de 70 vídeos de shows, missas, músicas, depoimentos, testemunhos e outros. A página é classificado no próprio Youtube como o canal oficial de música do padre Reginaldo Manzotti. Possui mais de um milhão de visualizações dos seus vídeos, desde quando aderiuà rede, em 28 de janeiro de 2014. Ao mesmo tempo em que desempenha uma ação ativa e dinâmica na web 2.0, consegue atrair a participação ativa de seus seguidores como poderemos observar nas tabelas que serão exibidasno próximo tópico.

\section{DISCURSO RELIGIOSO, PROMOÇÃO E MARKETING PARA A CONSTRUÇÃO DA IMAGEM DE UM POPSTAR CATÓLICO}

Por mais opulenta que seja uma economia, por mais que produza, sempre vai produzir frustração, infelicidade e insatisfação, porque sua produção ilimitada de bens está muito intimamente ligada a produção ilimitada de necessidade (SLATER, 2002, p. 79).

$\mathrm{Na}$ busca por atender as demandas dos consumidores, colocando a atenção às suas necessidades como meta, as instituições religiosas e seus personagens estabelecem complexos sistemas de estratégias midiáticas, que visam não apenas disseminar a sua fé e doutrina, mas promover suas marcas, vender seus produtos e serviços e atrair a adesão de novos fãs. No contexto cultural midiático on-line, Reginaldo Manzotti não é apenas mais um padre, ele é uma marca, uma forte identidade, bem representada pelos elaborados conteúdos de mídias disponibilizados na rede. 


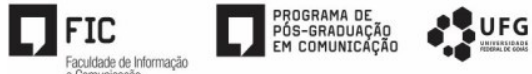

A partir da análise de uma amostra de discursos compartilhados na fanpage do padre no Facebook, é possível observar como estes são construídos com um tom impessoal e com maioria de postagens voltadas para a promoção do personagem, o padre cantor em questão. Acredita-se que esta ênfase na dimensão promocional presente nos discursos dos perfis de Manzotti na rede, estimule o consumo de conteúdos que são de alguma forma vinculados ao nome do padre. Destacamos a visão de Campbell (2001) sobre consumo, pois traz a ideia de que existe no mundo moderno uma necessidade constante e incessante por prazer ou um "hedonismo moderno", como o autor classifica. Para Campbell (2001, p. 97): “A princípio, a resposta do hedonista tradicional, quando colocado diante da perda do prazer que ocorre naturalmente como consequência da satisfação garantida, é a tentativa de recriar artificialmente o ciclo em que se experimentavam satisfação e carência”, este ciclo de insaciabilidade aparenta direcionar fluxos para um futuro incerto, e a sensação de incerteza é extremamente característica desse tempo em que estamos imersos. Esta carência a que se refere Campbell (2001) reforça, nos dias de hoje, a importância da fé religiosa para a sustentação da vida moderna, tão repleta de frustrações e negação de direitos.

Das amostras colhidas no Facebook, apresentam-se postagens que podem ser agrupadas em seis categorias diversas, são elas: instruções para contribuição econômica, promoção de programas, agenda litúrgica, conteúdo que promove a submissão à fé/mensagem religiosa,divulgaçãode músicas epromoção de eventos. A fanpage, de fato, funciona como espaço para promoção dos programas, músicas e imagem do padre Manzotti.

Dos seis grupos de conteúdos exibidos na tabela a seguir como amostra, cinco são de ênfase promocional, e um com instruções para que os fiéis possam contribuir economicamentepara a Associação que o padre coordena. As fanpages, por suas ênfases no mundo das celebridades e das abordagens mercantis, nutrem uma visão de mundo bem característica da atual sociedade do espetáculo (DEBORD, 1997). Tal contexto não exclui os líderes religiosos da contemporaneidade, que constroem e consolidam a teia que compõe a nova cultura religiosa 2.0, bastante demarcada pelos conteúdos de autopromoção de suas personalidades célebres: conteúdos predominantemente imagéticos ede umdiscurso proselitista, que amplia o religioso fundante paraum espaço que é também de interação e participação dos fiéis - a julgar pelos números das interações, como se pode também observar nos exemplos da Tabela 1. 
Tabela 1 - Postagens realizadas na fanpage do padre Reginaldo Manzotti no Facebook, no período entre fevereiro de 2015 e setembro de 2014

\begin{tabular}{|c|c|c|c|c|c|}
\hline Postagem exemplo & $\begin{array}{l}\text { Data } \\
\text { Publicacão }\end{array}$ & Curtidas & Comp. & Coment. & Categoria \\
\hline $\begin{array}{l}\text { Como contribuir com a Obra } \\
\text { Evangelizar é Preciso - Erro no } \\
\text { Boleto Bancário } \\
\text { \#EvangelizaréPreciso }\end{array}$ & $20 / \mathrm{Fev} / 2015$ & 14.323 & 470 & 449 & $\begin{array}{l}\text { Intruções para } \\
\text { contribuíção } \\
\text { econômica }\end{array}$ \\
\hline $\begin{array}{l}\text { Se você não conseguiu ouvir o } \\
\text { último bloco do programa } \\
\text { Experiência de Deus de hoje, } \\
\text { acompanhe no vídeo e faça o } \\
\text { primeiro dia da Novena de São } \\
\text { Sebastião. } \\
\text { \#ExperiênciadeDeus\#novena }\end{array}$ & 19/jan/2015 & 102.914 & 27.233 & 5.658 & $\begin{array}{l}\text { Promoção de } \\
\text { programas }\end{array}$ \\
\hline $\begin{array}{l}\text { Hoje damos início as festividades } \\
\text { do Jubileu de Diamante do } \\
\text { Santuário Nossa Senhora de } \\
\text { Guadalupe. Acompanhem na TV } \\
\text { Evangelizar a Santa Missa } \\
\text { Solene, a partir } \\
\text { das19h30. \#EvangelizaréPreciso \# } \\
\text { NSGuadalupe }\end{array}$ & 12/dez/2014 & 33.546 & 5.422 & 1.144 & $\begin{array}{l}\text { Promoção de } \\
\text { agenda } \\
\text { eucarística }\end{array}$ \\
\hline $\begin{array}{l}\text { "Poderíamos aconselhar este } \\
\text { servo a ir ao sindicato e pedir } \\
\text { conselhos sobre o que fazer com } \\
\text { um patrão assim, mas Jesus disse: } \\
\text { 'Não, o serviço é total, porque Ele } \\
\text { fez caminho com sua atitude de } \\
\text { serviço; Ele é o servo. Ele se } \\
\text { apresenta como o servo, aquele } \\
\text { que veio para servir e não para ser } \\
\text { servido': é o que diz, claramente. } \\
\text { [...] Baseado no Evangelho de } \\
\text { hoje (Lc 17,7-10), Papa Francisco } \\
\text { nos convida a seguir o exemplo } \\
\text { de Jesus que se apresenta como o } \\
\text { servo [...] (Homilia Papa } \\
\text { Francisco 11/11/2014). }\end{array}$ & 11/nov/2014 & 114.726 & 8.712 & 2.720 & $\begin{array}{l}\text { Mensagem } \\
\text { religiosa } \\
\text { promove a } \\
\text { submissão à fé }\end{array}$ \\
\hline $\begin{array}{l}\text { Reze pela sua família com o } \\
\text { Padre Reginaldo Manzotti na } \\
\text { música "Bênção do Lar" } \\
\text { "Derrama Senhor Tuas bênçãos } \\
\text { Derrama Senhor no meu lar } \\
\text { O amor que nos une na dor } \\
\text { Nossas forças refaz" } \\
\text { Padre Reginaldo Manzotti - } \\
\text { Bênção do Lar (DVD Milhões de } \\
\text { Vozes Ao Vivo em Fortaleza) }\end{array}$ & $\begin{array}{l}\text { 03/out/2014 } \\
\text { Em outubro } \\
\text { foram } \\
\text { realizadas } \\
\text { muitas } \\
\text { publicações } \\
\text { com vídeos } \\
\text { de shows do } \\
\text { Padre }\end{array}$ & 44.277 & 8.697 & 1.370 & $\begin{array}{l}\text { Divulgação de } \\
\text { suas músicas }\end{array}$ \\
\hline $\begin{array}{l}\text { Faltam quatro dias para o I Retiro } \\
\text { Evangelizar é Preciso em São } \\
\text { Paulo! Faça sua inscrição através } \\
\text { do site: } \\
\text { http://www.padrereginaldomanzot } \\
\text { ti.org.br/retiro sp }\end{array}$ & $10 /$ set $/ 2014$ & 41.538 & 4.098 & 1.299 & $\begin{array}{l}\text { Promoção de } \\
\text { evento }\end{array}$ \\
\hline
\end{tabular}

Fonte: Fanpage de Reginaldo Manzotti no Facebook,em:<https://www.facebook.com/padrereginaldomanzotti $>$. 
Como dito anteriormente, dos conteúdos aqui apresentados, apenas um não está diretamente ligado à publicização e promoção dos produtos culturais do padre Manzotti. Neste, vemos o evangelho citado, em referênciaao Papa Francisco, que remete a mensagem de fé e submissão, evidenciando a face do discurso que sugere as diretrizes do proceder cristão: "Não, o serviço é total, porque Ele fez caminho com sua atitude de serviço; Ele é o servo. Ele se apresenta como o servo, aquele que veio para servir e não para ser servido" ${ }^{13}$, ao colocar Jesus numa posição de servidor, o discurso sugere a todos os fiéis o mesmo comportamento. O que nos leva a afirmar que o espaço digital se propõe a cumprir, igualmente, o papel que antes estava destinado às interações físicas, quando os líderes religiosos instruíam e admoestavam seus fiéis acerca das doutrinas da fé que decidiram abraçar.

A maioria dos conteúdos que são postados no Facebook são replicados no Twitter, o que termina gerando uma sensação de equivalência entre as duas redes. Aparentemente não há uma estratégia que diferencie o discurso dessas redes utilizadas pelo padre. Na amostra aqui apresentada composta por seis publicações feitas no perfil do Twitter de Reginaldo Manzotti (Tabela 2), três dessas publicações promovem os programas e as músicas do padre, as outras três amostras apresentam trechos de oração.

É válido ressaltar que as orações aqui apresentadas parecem confirmar o que afirmou Campbell (2001), sobre a perda do prazer e carência que, experimentada pelos consumidores, gera nesses a necessidade de busca incessante por novas formas de alívio, satisfação. Nos exemplos "Socorrei-nos em nossas necessidades, alivie-nos nas nossas angústias" e "Protejame Senhor e renova minha vida", as palavras apresentam uma atmosfera que aparenta oferecer conforto e renovação de esperanças e, consequentemente, auxiliando no desenvolvimento de novos desejos. Tudo isso, numa clara transposição para espaços que agora adquirem certa sacralidade, outrora destinada apenas aos espaços dos templos.

Nas publicações que remetem a promoção, percebe-se estratégias de geração de expectativa, linguagem imperativa (que se utiliza de verbos nesse tempo como "abençoa", "proteja", "ouça”), de tom interrogativo, que gera o sentimento de que há, muito mais do que a preocupação com a opinião do fiel, mas com a sua participação e presença naquele ambiente on-line; estimula-se a reflexão, o pensar religioso acerca dos desígnios de Deus para a vida dos crentes. Em paralelo, observamos um processo de venda dos programas e das músicas, quando

\footnotetext{
${ }^{13}$ Postagem de 11 de novembro de 2014, realizada na fanpage do Padre Manzotti, conforme citado na tabela 1.
}

Comun. \& Inf., Goiânia, GO, v. 18, n. 2, p. 36-52, jul./dez. 2015 
nos 140 caracteres permitidos pelo Twitter, são anunciados programas e lançamentos musicais do padre.

Tabela 2 - Publicações realizadas no perfil do Twitter do padre Reginaldo Manzotti, no período entre fevereiro de 2015 e setembro de 2014.

\begin{tabular}{|l|l|l|l|l|}
\hline Tweet & Data Publicação & $\begin{array}{l}\text { Nro. De } \\
\text { Curtidas }\end{array}$ & $\begin{array}{l}\text { Nro. De } \\
\text { Retweets }\end{array}$ & Categoria \\
\hline $\begin{array}{l}\text { Programa Fé em Debate no ar! O tema de } \\
\text { hoje é ansiedade. Qual a sua dúvida? } \\
\text { Ouça pela Rádio Evangelizar... } \\
\text { http://fb.me/3Y2VRHKJP }\end{array}$ & $22 /$ fev/2015 & 45 & 10 & $\begin{array}{l}\text { Promoção de } \\
\text { programas }\end{array}$ \\
\hline $\begin{array}{l}\text { Socorrei-nos em nossas necessidades, } \\
\text { alivie-nos nas nossas angústias, livre-nos } \\
\text { das enchentes, da seca e... }\end{array}$ & $20 /$ jan/2015 & 91 & 33 & $\begin{array}{l}\text { Palavras de } \\
\text { oração }\end{array}$ \\
\hline $\begin{array}{l}\text { Nesta quarta-feira (17), quero convidar } \\
\text { todos para rezar pelo Papa Francisco } \\
\text { que completa mais um ano de vida,... } \\
\text { http://fb.me/3xxHOtq65 }\end{array}$ & $17 /$ dez/2014 & 60 & 17 & $\begin{array}{l}\text { Pedido de } \\
\text { oração pelo } \\
\text { Papa }\end{array}$ \\
\hline $\begin{array}{l}\text { "Sou o Deus dos perseverantes O Deus } \\
\text { da Misericórdia" Música "Milagre no } \\
\text { Caixa Sete" no CD "Faça-me Crer". } \\
\text { Ouça... http://fb.me/2E0qbyG5W }\end{array}$ & $10 /$ nov/2014 & 58 & 9 & $\begin{array}{l}\text { Promoção de } \\
\text { suas músicas }\end{array}$ \\
\hline $\begin{array}{l}\text { Hoje no Experiência de Deus começamos } \\
\text { a Novena de Nossa Senhora Aparecida. } \\
\text { Qual a sua intenção? Somos todos... } \\
\text { http://fb.me/3O4p3xaLJ }\end{array}$ & $06 /$ out/2014 & 50 & 10 & $\begin{array}{l}\text { Promoção de } \\
\text { programas } \\
\text { Pergunta }\end{array}$ \\
\hline $\begin{array}{l}\text { Abençoa-me Jesus e me envia Teu } \\
\text { Espírito de Luz Proteja-me Senhor e } \\
\text { renova minha vida em Teu amor! } \\
\text { http://fb.me/1EfGHiO6A }\end{array}$ & $02 /$ set/2014 & 76 & 37 & $\begin{array}{l}\text { Palavras de } \\
\text { oração }\end{array}$ \\
\hline
\end{tabular}

Fonte: Perfil do Twitterdo padre Reginaldo Manzotti, disponível em: https://twitter.com/padremanzotti

Em uma análise histórica a partir da timeline (linha do tempo) de uma fanpage religiosa, podemos constatar que os discursos apresentam continuidades em relação à origem. Estas continuidades, sobre as quais Foucault (2008) já questionava por quais caminhos se puderam estabelecer e de que forma as estratégias discursivas podiam ser mantidas e constituídas "para tantos espíritos diferentes e sucessivos, um horizonte único”. Concluindo que -“o problema não é mais a tradição e o rastro, mas o recorte e o limite; não é mais o fundamento que se perpetua, e sim as transformações que valem como fundação e renovação dos fundamentos" (FOUCAULT, 2008, p. 06).

Assim sendo, não seria leviano da nossa parte ponderar que todas as religiões possuem, na raiz de seus discursos fundadores, a base para continuidades observadas nas práticas religiosas contemporâneas. Mas que, para se adequarem aos novos tempos do marketing em rede e do mercado religioso, passam a atuar de forma descontínua em relação às origens, demonstrando rupturas com os vínculos tradicionais; rupturas que Foucault (2008) relata como: 
recortes, limites, transformações e renovações, que ocorrem principalmente para promover as adequações ao novo cenário. $\mathrm{O}$ uso de instrumentos tecnológicos incorporados às práticas religiosas, por exemplo, caracteriza uma ruptura com a forma tradicional de fazer comunicação nesse campo.

Com efeito, além da observação da existência de rupturas e continuidades discursivas, presentes nos conteúdos religiosos e nas práticas das redes sociais digitais, também se evidencia a aplicação de um poder simbólico exercido por meio do "título pessoal" que detêm o padre Reginaldo Manzotti e que instaura o seu "lugar de fala". De acordo com Bourdieu (2011, p. 146-147) “do outro lado está o ponto de vista autorizado, a título pessoal, como certo grande crítico, certo prefaciador de prestígio ou certo autor consagrado (“J'accuse") e, sobretudo, o ponto de vista legítimo do porta-voz autorizado [...]", a pessoa que fala do outro lado, em todo caso, é o padre cantor, celebridade católica, reconhecido e respeitado pelos fãs-fiéis. Essa imagem de porta-voz é ao mesmo tempo refutada e reproduzida por meio da atuação na web na sua reconfiguração das formas religiosas contemporâneas.

A partir dessabreve análise de discursos extraídos das redes sociais do padre Manzotti é possível refletir sobre várias questões que envolvem a ideia de religião 2.0, dentre estas, a de que nunca a "religião de mercado" esteve tão evidente como na era da "digital religion", o mercado, aliás, parece ser a razão de permanência da religião no ambiente $w e b$, situação distinta da ideia de "propagação do evangelho à todas as criaturas", como preconizou a Bíblia.

Na contramão do objetivo cristão fundante (o alcance e resgate das almas), a atividade de construção de uma imagem de popstar religioso se revela na rede. Através das fotografias, aparentemente selecionadas com estima e visão mercadológica; dos vídeos, produzidos de forma bastante profissional; e dos ares propagandísticos dos conteúdos reproduzido nos perfis dos líderes religiosos de hoje.

\section{MÍDIAS DIGITAIS E INTERAÇÕES NOS ESPAÇOS DE FÉ CATÓLICA: CIBER- IGREJAS E CIBER-FIÉIS}

Ao analisar os ambientes discursivos atribuídos ao padre Manzotti na internet, observamos, corroborando com a ideia da interatividade como característica essencial da web 2.0, que todos os seus espaços virtuais possibilitam e requerem a participação do usuário. Conforme acena Primo (2013, p. 27), “é preciso observar-se como os interagentes envolvidos negociam suas posições de produção e recepção e como eles se alternam (as condições de interação)". Como descrito anteriormente, mesmo o site, que seria um modelo de mídia digital

Comun. \& Inf., Goiânia, GO, v. 18, n. 2, p. 36-52, jul./dez. 2015 


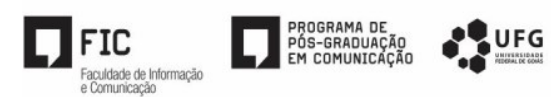

mais estático, possui espaços nos quais é possível interagir, deixando depoimentos, por exemplo, ou utilizar aplicativos e participar das atividades lúdicas propostas por estes. Primo (2013) observa ainda que mudanças estão ocorrendo na âmbito da ideia de polos contraditórios de emissão, ao inferir: "Ao que tudo indica, as fronteiras entre o que antes era visto como polos que se negavam vêm sendo de fato borradas" (PRIMO, 2013, p. 19). O autor observa que a democratização dos meios vem favorecendo esse processo, em que os usuários da rede passam a contribuir tanto para a a sua composição, como as corporações que da rede fazem o seu negócio.

A observância da interatividade nas práticas da religião 2.0 incorre na oportunidade de debate de dois outros conceitos que a nossa reflexão persegue, o de ciber-igreja e o de ciberfiel, como elementos fundamentais para pensar a religião 2.0. Ambos são prioritariamente caracterizados pelas possibilidades interativas, afinal, não seria possível pensar uma ciberigreja sem as ações colaborativas dos ciber-fiéis.

Assim, o nosso olhar se volta para um tipo de usuário da web 2.0 que classificamos como ciber-fiel, por fatores que pretendemos aqui demonstrar. Este indivíduo navega na rede e desenvolve práticas religiosas exercidas no ambiente digital, substituindo inclusive práticas religiosas cotidianas. $\mathrm{O}$ ambiente das mídias sociais digitaismedia os processos de interação entre internautas, facilitando, amplificando tais processos comunicacionais e promovendo a participação e o relacionamento.

Essa não é uma percepção nova no campo dos estudos dos meios on-line, Santaella (2004) vê na interatividade um dos tópicos centrais da comunicação digital. O ciber-fiel, na nossa acepção, é um praticante da religião 2.0, seus usos do ambiente web incluem manifestações religiosas diversas nas redes sociais digitais. Não por acaso, Aoki e Machado (2010) o descrevem como um indivíduo que usa os recursos digitais em seu contato com o divino. Uma ciber-religião, como definida por Miklos (2012, p. 8) como a dimensão "virtual das comunidades religiosas".

Ao articular os dois conceitos podemos entender a ciber-religião, ou religião 2.0, como uma série de práticas e crenças, semelhantes e aceitas, que são desenvolvidas no ciberespaço pelo ciber-fiel ${ }^{14}$. Essa reflexão incorre em um terceiro conceito, pois,após atestar a presença dos elementos: religião e fiel na web, é preciso olhar também para os lugares de convergência das práticas, em quais ocorre a partilha da experiência religiosa, a participação na construção

\footnotetext{
${ }^{14}$ Essa definição também foi pensada a partir do concepção de religião de Durkheim (1989), combinada ao conceito de ciber-religião de Miklos (2012).
}

Comun. \& Inf., Goiânia, GO, v. 18, n. 2, p. 36-52, jul./dez. 2015 


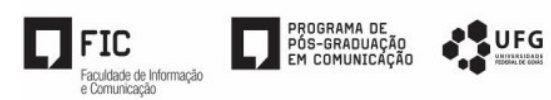

do pensamento, as interações e fluxos de informações, todas estas questões se convertendo em atos de fé e relacionamento, através das comunidades digitais, compondo o lugar desses encontros no ambiente web que percebemos como ciber-igrejas.

Observando, portanto, a presença da religião nas redes sociais digitais na perspectiva do mercado, poderemos perceber ações muito particulares da dimensão da ciber-igreja e seu relacionamento/interação com os fiéis no ambiente da web. Enquanto as igrejas continuam predeterminando os princípios éticos e morais de suas comunidades religiosas, ou conforme Weber postula (1978, p. 45), "seu poder diretriz se funda no monopólio do outorgamento ou negação dos valores sagrados", sendo o espaço das redes sociais um dos elementos de viabilização para a continuidade desse monopólio, continuidade permitida em parte pelas ações de marketing de relacionamento. O ciber-fiel, internalizando esses valores, os reproduzem em atos interativos de demonstração da aprovação das palavras proferidas por seus líderes religiosos, conferindo poder legitimador daquilo que é manifestado pela religião em questão.

Todas as composições teóricas realizadas nesse texto auxiliam também na reflexão sobre a dinâmica relação de oferta e demanda entre ciber-igrejas e ciber-fiéis. Os milhares de sites, blogs e perfis em redes sociais que têm a religião como tema fundador, oferecem basicamente discursos, nos formatos mais diversos, desde textos e vídeos até aplicativos e imagens animadas, porém, em nossa percepção, os espaços virtuais que mais caracterizam as ciber-igrejas, são as páginas que possibilitam a participação e interação com os fiéis.

Entendemos, por conseguinte, que os ciber-fiéis - como todos os indivíduos que interagem favoravelmente com as mídias sociais religiosas e as seguem -se diferenciam pelos graus de autonomia de voz, pela intermediação da internet epela interação com outros fiéis, sem necessariamente estar presencialmente próximos. No ambiente da web 2.0, as ciber-igrejas disponibilizam seus conteúdos discursivos para serem consumidos. Tais instituições se arriscam num território em que a liberdade de expressão é pressuposto básico. Nos espaços digitais das ciber-igrejas o discurso toma sentidos diversos, desde pregações à conteúdos evidentemente publicitários, alguns apresentam até um conteúdo mais pessoal.

O contexto apresentado até aqui nos confere elementos para responder à questões levantadas no início do texto: a religião 2.0 diferencia-se pelas vias da interatividade? Da ampla diversidade? Da premente e constante ação mercadológica que propaga? Da sua íntima relação com a cultura das mídias digitais? Ou de tudo isso?

Com efeito, a religião 2.0 toma forma por meio da ação das diversas instituições religiosas presentes na esfera web e dos seus usuários interatores, razão de ser das instituições

Comun. \& Inf., Goiânia, GO, v. 18, n. 2, p. 36-52, jul./dez. 2015 
na web. Acreditamos que a ação da religião 2.0 interfere tanto no fazer religião como no praticar da religiosidade nessa nova esfera virtual. Assim sendo, as celebridades religiosas encontram na rede o lócus ideal para a promoção de suas ideias e atividades, bem como espaço propício para a consolidação de uma nova identidade institucional.

\section{CONSIDERAÇÕES FINAIS}

Com vistas a uma reflexão sobre o que se convencionou chamar de religião 2.0, seguimos um percurso teórico e metodológico que arriscou circular o tema na transição por campos do saber que se interessam pelo termo, ou por suas variações.

Dessa forma, elegemos como exemplo para observação um personagem desse cenário religioso web, que soube se apropriar adequadamente dos meios disponíveis pela rede para a promoção de sua imagem. A pesquisa apontou, dentre outras questões importantes, que a religião 2.0 é também uma religião da interação e colaboração.

Essa religiosidade de segunda geração da $w e b$, abre espaço para a materialização de elementos simbólicos, viabiliza a emergência de ciber-igrejas e ciber-fiéis, instaura novas formas de crer e viver a dimensão ritualística da fé, mas não só isso, ela promove personalidades religiosas célebres, estes auxiliam na descrição do fenômeno, pois acabam se tornando figuras integrantes fundamenteis na constituição de uma religião digital.

Acreditamos, contudo, que essa discussão não se esgota aqui, pelo contrário, este é o passo inicial para a compreensão do que está acontecendo atualmente com o cenário religioso, que não está consolidado e que se desenvolve como esboço de uma nova forma de agir e fazer religiosos modernos.

\section{REFERÊNCIAS}

AOKI, C.; MACHADO, F. R. Acesso ao divino: a utilização de recursos digitais para práticas religiosas católicas. Revista de Estudos da Religião, São Paulo, ano. 10, p. 106-122, set. 2010.

BOURDIEU, P. O poder simbólico. Rio de Janeiro: Bertrand Brasil, 2011.

CAMPBELL, C. A ética romântica e o espírito do consumismo moderno. Rio de Janeiro: Rocco, 2001

DEBORD, G. A sociedade do espetáculo. Rio de Janeiro: Contraponto, 1997.

DURKHEIM, É. As formas elementares da vida religiosa. São Paulo: Paulinas, 1989.

FOUCAULT, M. A arqueologia do saber. Rio de Janeiro: Forense Universitária, 2008. 
CAMPBELL, A. H. Digital religion: understanding religious practice in new media worlds. New York: Routledge, 2013.

LEMOS, A. Cibercultura: tecnologia e vida social na cultura contemporânea. 6. ed. Porto Alegre: Sulina, 2013.

LEVY, P. O que é o virtual. São Paulo: Ed. 34, 1996.

MIKLOS, J. Ciber-religião: a construção de vínculos religiosos na cibercultura. Aparecida: Ideias e Letras, 2012.

BRONSZTEIN, K. R. M. P. P. Nação dos 318: a religião do consumo na igreja universal do reino de deus. Comunicação mídia e consumo, São Paulo, ano 11, v. 11, n. 30, 2014.

SALUSTIANO, A. M; BRONSZTEIN, K. R. M. P. P. A consonância entre a religião e a sociedade de consumo na Bola de Neve Church. In: CONGRESSO INTERNACIONAL COMUNICAÇÃO E CONSUMO, 4., 2014, São Paulo. Anais... São Paulo: Comunicon, 2014.

PRIMO, A. Interações mediadas e remediadas: controvérsias entre as utopias da cibercultura e a grandeindústria midiática. In: PRIMO, A (Org.). A internet em rede. Porto Alegre: Sulina, 2013. p. $13-32$.

SANTAELLA, L. Navegar no ciberespaço: o perfil cognitivo do leitor imersivo. São Paulo: Paulu, 2004.

SBARDELOTO, M. Interações em rituais on-line católicos: uma análise da prática religiosa em tempos de internet. In: RIBEIRO, J. C. (et. al.). Mídias sociais: saberes e representações. Salvador: EDUFBA, 2012.

SLATER, D. Cultura do consumo \& modernidade. São Paulo: Nobel, 2002.

SPADARO, A. Ciberteologia: pensar o cristianismo nos tempos da rede. São Paulo: Paulinas, 2012.

WEBER, M. Sociologia de la religion. Buenos Aires: La Pléyade, 1978.

WOLTON, Dominique. Internet, e depois? Uma teoria crítica das novas mídias. 3. ed. Porto Alegre: Sulina, 2012.

Recebido em: 22/07/2015

Aceito em: 08/10/2015

Publicado em: 04/12/2015 